\title{
Impact of 4D-variational assimilation of WOCE hydrography on the meridional circulation of the Indian Ocean
}

\author{
Bruno Ferron $^{\kappa_{2} a}$ and Jochem Marotzke ${ }^{-b}$
}

a Laboratoire de Physique des Océans, UMR 6523 CNRS/IFREMER/UBO, IFREMER Brest, France
${ }^{\mathrm{b}}$ School of Ocean and Earth Science, Southampton Oceanography Centre, UK

*: Corresponding author : IFREMER, DRO/LPO, BP 70, 29280 , Plouzané, France

\begin{abstract}
:
World Ocean Circulation Experiment (WOCE) hydrographic sections and a sea-surface climatology are combined with a ocean general circulation model through a 4D-variational method to analyze the meridional overturning of the Indian Ocean. The regional model is run with realistic surface forcings over year 1995 for which most of WOCE Indian Ocean sections were made. The assimilation controls the initial temperature and salinity fields, surface forcings and open-boundary velocities, temperature and salinity. When no observations are assimilated, the model shows that the deep (below $1000 \mathrm{~m}$ ) meridional overturning is weak compared to observation-based estimates. This is a common feature of general circulation models. In contrast, after the assimilation, the model develops a deep overturning of $17 \times 10^{6} \mathrm{~m}^{3} \mathrm{~s}^{-1}$ at $32^{\circ} \mathrm{S}$ when a $10 \times 10^{6} \mathrm{~m}^{3} \mathrm{~s}^{-1}$ Indonesian Throughflow (ITF) is prescribed. The mass flux of bottom waters that moves northward below $3200 \mathrm{~m}$ is balanced by a southward mass flux of deep waters between 1000 and $3200 \mathrm{~m}$. The deep overturning carries $10 \%$ of the total southward energy flux of $1.2 \mathrm{PW}$ at $32^{\circ} \mathrm{S}$. The intensity of this deep overturning changes only by $\pm 2 \times 10^{6} \mathrm{~m}^{3} \mathrm{~s}^{-1}$ when the annual mean ITF is zero or $30 \times 10^{6} \mathrm{~m}^{3} \mathrm{~s}^{-1}$. The upper circulation is less constrained by the assimilation because of the large temporal and spatial variability of this ocean and also because of limitations in the representation of the mixed layer physics during the assimilation process. Limitations in the physics of the model also are thought to be the source of the slow erosion of the deep overturning when the model is run for several years from its optimal state.
\end{abstract}




\section{Introduction}

The meridional overturning circulation (i.e. zonally integrated circulation) of the Indian Ocean is still the subject of a large range of estimates. Such a description of the circulation, although it remains basic, is an important parameter since it gives the overall budget of various properties for a given basin, thus ranking the role of the basin in the global balance. Because the Indian Ocean has been less observed than other oceans, there remains large uncertainties concerning the structure and intensity of its meridional overturning. Especially, estimates from hydrographic inversions are not consistent with the picture given by ocean general circulation models. These two approaches particularly differ in their representation of the deep circulation below $1000 \mathrm{~m}$.

On the one hand, inverse models based on hydrographic oceanic transects show that there exists a deep overturning in the Indian Ocean. The magnitude of this deep overturning at $32^{\circ} \mathrm{S}$ is estimated to be $10.1 \times 10^{6} \mathrm{~m}^{3} \mathrm{~s}^{-1}$ (Bryden and Beal 2001), $11 \pm 4 \times 10^{6} \mathrm{~m}^{3} \mathrm{~s}^{-1}$ (Ganachaud et al. 2000), $12 \pm 3 \times 10^{6} \mathrm{~m}^{3} \mathrm{~s}^{-1}$ (Robbins and Toole 1997), $17 \pm 5 \times 10^{6} \mathrm{~m}^{3} \mathrm{~s}^{-1}$ (Macdonald 1998), $23 \pm 3 \times 10^{6} \mathrm{~m}^{3} \mathrm{~s}^{-1}$ (Sloyan and Rintoul 2001). Older estimates widen the range of possible values (Fu 1986; Toole and Warren 1993). Such estimates depend on the choice of hydrographic lines, properties and their conservation equations (constraints), free parameters (control variables), and the weight given to each constraint. These estimate are questionable because most of these studies i) assume that the circulation is stationary, ii) combine hydrographic lines that are taken at different seasons and years, iii) use simplistic physics.

On the other hand, ocean general circulation models only show weak deep overturning (Wacongne and Pacanowski 1996; Garternicht and Schott 1997; Lee and Marotzke 1997, 1998; Zhang and Marotzke 1999). These model estimates are also questionable because models i) suffer from subgrid-scale parameterizations that generate model errors, ii) are blended with surface forcing errors, iii) are started from smoothed climatologies that cannot represent the major boundary currents accurately.

We propose to reconcile the two approaches by using a general circulation model to assimilate 
the recent WOCE hydrography of the Indian Ocean. We use a 4D-variational method (e.g. Le Dimet and Talagrand, 1986; Thacker and Long 1988) that exploits the dynamics of an ocean general circulation model to propagate information contained in the observations distributed in time and space. This method naturally links all available observations with each other to produce an estimate in which observations are consistent with the dynamics of the model. This study focuses on the impact produced by the assimilation of WOCE hydrography on the deep meridional overturning circulation. Although some other typical characteristics of the Indian Ocean circulation are given, the detailed description of the circulation is left for a subsequent study.

We start with a description of the model and assimilation setup (part 2). Major characteristics of the circulation without assimilation are described (part 3) followed by a presentation of the minimization procedure (part 4). Our estimated circulation is then presented (part 5) and discussed $($ part 6).

\section{Configuration of the experiment}

The 4D-variational approach is an iterative process that uses a forward model and the adjoint of its tangent-linear model. The time integration of the forward non-linear model gives a measure (or cost function) of the cumulated misfits between the data and their model analogues in a least square sense. The data consist of observations and also include the first guess. Model-data misfits are weighted by some error covariances. In this study, all the error covariance matrices are diagonal, that is, there is no correlation between two different data. Model-observations misfits act as constraints on the adjoint model. The backward time integration of the adjoint gives the gradient of the cost function to some independent variables of the model (or control variables). A descent algorithm is then used to calculate the amplitude of the independent variables so that, at the next iteration, the model trajectory is closer to the observations. Iterations are stopped as soon as the model trajectory is consistent with the observations. The estimated trajectory is then optimal with respect to the constraints. For further details about the method, the reader is referred 
to Le Dimet and Talagrand (1986) and Thacker and Long (1988). Observations are composed of the WOCE hydrography and the monthly Levitus (1994) sea surface climatology. As the WOCE hydrography was measured nearly over a one year-long time period, the forward and adjoint models are integrated during one year at each iteration to respectively produce the cost function and its gradient. Using a one year time window is necessary to propagate the information contained in the sparse observations through the assimilation scheme. A shorter time window would contain less observations which would be insufficient to act as a constrain on the model.

\subsection{Configuration of the forward and adjoint models}

This work uses the M.I.T. ocean general circulation model (Marshall et al. 1997ab) which is based on the primitive equations under the Boussinesq approximation. The Indian Ocean domain extends from $\left(24^{\circ} \mathrm{E}, 35^{\circ} \mathrm{S}\right)$ to $\left(122^{\circ} \mathrm{E}, 26^{\circ} \mathrm{N}\right)$ (Fig. 1). The horizontal resolution is $1^{\circ}$ with 22 levels in the vertical (10 $\mathrm{m}$ resolution near the surface down to $500 \mathrm{~m}$ for the last six levels). The model bathymetry is interpolated from ETOPO5 data (1988). Mixing processes are parameterized through a convection algorithm and constant eddy diffusivity coefficients $\left(K_{h}^{d y n}=2 \times 10^{4} \mathrm{~m}^{2}\right.$ $\mathrm{s}^{-1}, K_{v}^{d y n}=2 \times 10^{-3} \mathrm{~m}^{2} \mathrm{~s}^{-1}, K_{h}^{\text {trac }}=K_{h}^{d y n} / 20, K_{v}^{\text {trac }}=K_{v}^{d y n} / 100$ where $K_{h}$ is the horizontal diffusivity, $K_{v}$ is the vertical diffusivity, superscript dyn stands dynamics and trac for tracers).

Prescribed open boundaries are set up at $35^{\circ} \mathrm{S}$ and at $122^{\circ} \mathrm{E}$ allowing for an Indonesian throughflow to exist. Open boundary velocities are interpolated from Stammer et al. 's (1997) global ocean circulation estimate. These open boundary velocities were corrected to have no net mass transport divergence. Temperature and salinity at the open boundary are prescribed from Levitus et al. (1994)'s climatology to be consistent with the spin-up that uses restoring towards Levitus'climatology. During a run, open boundaries are linearly interpolated from monthly velocity and tracer (temperature and salinity) fields. Twice-daily winds and daily heat and freshwater fluxes from re-analyses of the National Center for Environmental Prediction (NCEP) force the ocean surface. Velocities at the open boundaries and surface forcings correspond to year 1995 to 
be consistent with WOCE hydrography.

The adjoint of the primitive equation model (Marotzke et al. 1999) is generated with the tangentlinear and adjoint model compiler (Giering and Kaminski 1998). A quasi-Newton method (Gilbert and Lemaréchal 1989) is used to compute changes in the control variables. Because the cost function is not sensitive to the velocities at the open boundary when observations (CTDs and sea surface properties) are assimilated, the assimilation is split into two steps. The first step assimilate observations to control the initial guess in temperature and salinity, tracers at the open boundary and surface forcings. Changes in the control variables induced by step one produces a new first guess in which the interior (away from the open boundaries) circulation is not consistent with velocities at the open boundaries. Starting from this new first guess, step 2 controls open boundary velocities under the constraint that those velocities must be consistent with the interior flow. Ideally, all constraints should be applied in one step. But, because the assimilation of the hydrography generates large changes in the initial guess stratification in step one, an adjustment occurs during the first two months of time integration. Demanding open boundary velocities to be consistent with the interior flow during the adjustment period (which happens when all constraints are applied simultaneously) produces spurious recirculation near the open boundary. That is why we decided to apply this constraint in a second step, starting from a first guess in which the dynamics is balanced by interior stratification. Note that the development of a multivariate assimilation

scheme that produces geostrophycally balanced control variables would be a solution to apply all constraints in one step.

\subsection{Step 1: Control of the initial guess, tracers at the open boundary, and surface forcings}

During the first step, a series of iterations is performed with the WOCE hydrography (Fig. 1) and the monthly Levitus sea surface temperature and salinity as observations. Most of the CTD lines were occupied during year 1995 except few of them which were done at the beginning of year 1996 
(before the 22th of January). In the assimilation, it has been assumed that the 1996-measurements were made at the same time as the last 1995-measurement (31th of December). Hence, in the following, only year 1995 is simulated.

During the first step, the control variables are the initial temperature and salinity 3D-fields, the time varying temperature and salinity at the open boundaries, and the surface forcings. Surface forcings are controlled once every twelve days to limit the size of the problem (note that twelve days is of the order of the decorrelation time of the atmosphere which is consistent with our simplification that errors are uncorrelated). Linear interpolation is applied between the timesteps where the surface forcings are controlled. Open boundaries are controlled monthly, that is with the same frequency as their forcing. The cost function reads:

$$
\begin{aligned}
J_{1}= & X_{T_{0}}^{T} B_{T_{0}}^{-1} X_{T_{0}}+X_{S_{0}}^{T} B_{S_{0}}^{-1} X_{S_{0}} \\
& +X_{T o b}^{T} B_{T o b}^{-1} X_{T o b}+X_{S o b}^{T} B_{S o b}^{-1} X_{S o b} \\
& +X_{\tau_{x}}^{T} B_{\tau_{x}}^{-1} X_{\tau_{x}}+X_{\tau_{y}}^{T} B_{\tau_{y}}^{-1} X_{\tau_{y}} \\
& +X_{h f}^{T} B_{h f}^{-1} X_{h f}+X_{E-P}^{T} B_{E-P}^{-1} X_{E-P} \\
& +\left(T_{\text {model }}-T_{C T D}\right)^{T} R_{T_{C T D}}^{-1}\left(T_{\text {model }}-T_{C T D}\right) \\
& +\left(S_{\text {model }}-S_{C T D}\right)^{T} R_{S_{C T D}^{-1}}\left(S_{\text {model }}-S_{C T D}\right) \\
& +\left(\overline{S S T_{\text {model }}}-S S T_{\text {Levitus }}\right)^{T} R_{\overline{S S T_{\text {model }}}}^{-1}\left(\overline{S S T_{\text {model }}}-S S T_{\text {Levitus }}\right) \\
& +\left(\overline{S S S_{\text {model }}}-S S S_{\text {Levitus }}\right)^{T} R_{\overline{S S S_{\text {model }}}}^{-1}\left(\overline{S S S_{\text {model }}}-S S S_{\text {Levitus }}\right)
\end{aligned}
$$

where $X$ is a vector of deviations from control variables, B is the error covariance matrix relative to the control variables, $\mathrm{R}$ is the error covariance matrix for the observations, $T_{0}\left(S_{0}\right)$ is the first guess 3D-temperature (salinity) field from which the model is initialized, Tob (Sob) is the first guess temperature (salinity) at the open boundary, $\tau_{x}\left(\tau_{y}\right)$ is the first guess zonal (meridional) wind stress, $h f$ is the first guess net heat flux, $E-P$ is the first guess freshwater flux, $T_{C T D}\left(S_{C T D}\right)$ are the CTD temperature (salinity) profiles and $T_{\text {model }}\left(S_{\text {model }}\right)$ their model 
counterpart, $S S T_{\text {Levitus }}\left(S S S_{\text {Levitus }}\right)$ are the monthly sea surface temperature (salinity) climatology and $\overline{S S T_{\text {model }}}\left(\overline{S S S_{\text {model }}}\right)$ their model counterpart.

During an iteration, the forward non-linear model is integrated over year 1995. During this integration, the cost function cumulates all model-observation misfits (last four terms in $J_{1}$ ) up to the last time-step (December 31th). Then, the adjoint model is integrated backward from the last day of December back to the first day of January. This adjoint run provides the cost function gradients with respect to the control variables. For instance, if the wind stress at day June 6 th 0h00 is a control variable, model-observation misfits occuring after this date will give an non-zero cost function gradient with respect to this control variable if those misfits are non-zero. Once the adjoint run is achieved, all the gradients are available and a descent algorithm is applied to get the amplitude of the deviation for each control variable. At the next iteration, our 3D wind stress field at day June 6 th $0 \mathrm{~h} 00$ will be its first guess value plus the corresponding $3 \mathrm{D}$ deviation calculated by the descent algorithm. Note that as error covariance matrices are diagonal, properties of the first guess fields are not conserved (like the wind curl for example).

During the first evaluation of the cost function (first iteration), the first eight terms of $J_{1}$, which penalize the deviation (i.e. drift) from the first guess, are zero since the control variables are zero; Only model-observation misfits force the adjoint equations. In subsequent iterations, the first guess is modified to decrease model-observation misfits. Hence for these iterations, both modelobservation misfits and deviations from the first guess force the adjoint equations. The first eight terms of $J_{1}$ prevent the assimilation from producing optimized control variables that are unrealistic relatively to our knowledge of uncertainties (contained in the error covariance matrix) on these control variables.

\subsection{Step 2: Control of velocities at the open boundary}

During the second step, the only control variables are the open boundary velocities. They are controlled under the constraint that vertical velocities along the open boundaries should not exceed generic values found in the interior. The cost function then reads: 


$$
J_{2}=X_{U o b}^{T} B_{U o b}^{-1} X_{U o b}+X_{V o b}^{T} B_{V o b}^{-1} X_{V o b}+{\overline{W_{o b}}}^{T} R_{W_{o b}}^{-1} \overline{W_{o b}}
$$

where $X_{U o b}\left(X_{V o b}\right)$ are deviations from the zonal (meridional) velocities at the open boundaries, $\overline{W_{o b}}$ are the monthly mean vertical velocities along the open boundaries.

Several sensitivity experiments have shown that the Indonesian Throughflow transport is not constrained by the data we assimilate. That is the gradient of the cost function to the throughflow transport is weak so that the assimilation scheme does not change it. Hence, this second step adjusts the open boundary velocities to the interior flow without controlling the throughflow transport.

For this second step to work, a new first guess needs to be built. Indeed, at the end of the first step, initial temperature and salinity fields have been modified so that the initial velocity fields are no more dynamically balanced. The new first guess is built by integrating the model during one year from the estimated parameters of the first step. This time integration is necessary to spin-up the model before launching step two. If this spin-up is not achieved, the initial adjustment that occurs within the first two months enters in the assimilation process of step two, and leads to spurious meridional recirculation along the open boundaries.

\subsection{Error covariances}

The depth-dependent errors in the CTD temperature and salinity are calculated as follow: For each vertical profile of CTD temperature and salinity, a local standard deviation profile was first calculated from profiles within a distance of two degrees and within a time of two weeks. The effect of internal waves was then added as a source of error assuming the internal wave spectra follows the Garrett and Munk (1975) spectra. A minimum error of $10^{-3} \mathrm{psu}$ is prescribed for the salinity. Profiles of the depth-dependent error that finally weights the model-CTD misfits (Fig. $2 \mathrm{ab})$ are the average of these local standard deviation profiles for the temperature and the salinity. They thus encompass changes due to time and subgrid-scale variability. These vertical profiles (Fig. 2ab) show that errors are the largest below the sea surface for both the temperature and the salinity. This is related to the position of the main thermocline and halocline located below 
the weak stratification of the first tens of meters. The main halocline is shallower than the main thermocline which explains the difference in maximum error depth. Note that the use of local standard deviation profiles instead of their average prevent the assimilation from converging to a consistent level because those profiles may vary too drastically from one profile too its neighbour. The use of the average of the local profiles produces smoother and more consistent changes in the control variables than when local profiles are used.

Errors in Levitus sea surface temperature and salinity are assumed spatially constant. They correspond to one fourth of the standard deviation of the difference between CTDs and their Levitus counterpart. This leads to an error of $0.5^{\circ} \mathrm{C}$ for the sea surface temperature and of 0.08 psu for the sea surface salinity. The factor one fourth was chosen to prevent sea surface properties from drifting when the model is started from the optimized state and run for several years.

Errors in the initial temperature and salinity (Fig. 2cd) are inferred from an average of standard deviations computed from the CTDs and their model counterpart taken from a prognostic run of one year started from the first guess. The depth-dependent profile obtained reflects large errors near the surface both in temperature and salinity. Same errors are taken for the open boundaries temperature and salinity since open boundaries are forced with Levitus climatology which is also used to construct the first guess.

Atmospheric models produce large relative errors in the heat and freshwater fluxes. For our assimilation, we took an error on those fluxes that is of the order of the standard deviation of the fluxes calculated over year 1995 and averaged over the whole domain. This gives an error in the heat flux of $80 \mathrm{~W} \mathrm{~m}^{-2}$ and of $1 \mathrm{~m} \mathrm{year}^{-1}$ for the freshwater flux. Errors in the wind stress are calculated as standard deviations from NCEP and ERS over year 1995. They are regional to enforce larger errors in the regions of monsoon.

For the second step, vertical velocities along the open boundaries larger than $10^{-5} \mathrm{~m} \mathrm{~s}^{-1}$ are penalized. Depth-dependent error profile in the open boundary velocities (Fig. 2e) are equal to 
the standard deviation calculated from the difference in velocities away from the open boundaries between one-year runs before and after step one.

\section{Ocean circulation without assimilation}

A 11-year long spin up of the model is obtained from starting the model at rest with the initial temperature and salinity fields taken from Levitus et al. (1994). The model undergoes 11 cycles of slightly modified year-1995 forcings. During the spin up, temperature and salinity are restored towards Levitus et al. (1994) in the first twelve levels to prevent the model from drifting. The restoring coefficient are set to one day at the surface, ten days at the second level and 30 days at deeper levels. The Indonesian Throughflow is forced to have an annual mean transport of $10 \times 10^{6} \mathrm{~m}^{3} \mathrm{~s}^{-1}$ with a seasonal variation in the range of $6 \times 10^{6} \mathrm{~m}^{3} \mathrm{~s}^{-1}$ (February) to $13 \times 10^{6} \mathrm{~m}^{3}$ $\mathrm{s}^{-1}$ (June). This Throughflow intensity is in the range of values estimated from observations and models. Gordon et al. (1999) reported a transport about 9 to $10 \times 10^{6} \mathrm{~m}^{3} \mathrm{~s}^{-1}$ for 1997 through the Makassar Strait which is considered as the main source of Pacific waters that feeds the Indonesian Throughflow. Since the interannual variability of the throughflow intensity might be important, the sensitivity of our estimated circulation to this parameter is investigated in section 5 .

Year-11 of the spin up is considered as the reference state of the forward model without assimilation. The model develops a circulation with an annual mean Agulhas Current transport of $75 \times 10^{6}$ $\mathrm{m}^{3} \mathrm{~s}^{-1}, 70 \times 10^{6} \mathrm{~m}^{3} \mathrm{~s}^{-1}$ during January and $78 \times 10^{6} \mathrm{~m}^{3} \mathrm{~s}^{-1}$ at the end of September. The Mozambique Channel carries an annual mean southward transport of $22 \times 10^{6} \mathrm{~m}^{3} \mathrm{~s}^{-1}$, with a minimum of $12 \times 10^{6} \mathrm{~m}^{3} \mathrm{~s}^{-1}$ during February and a maximum of $39 \times 10^{6} \mathrm{~m}^{3} \mathrm{~s}^{-1}$ during October. Eddies may contribute to a significant part of the transport through the Mozambique Channel (Biastoch and Krauß 1999). Although our model is not eddy-permitting, its Mozambique Channel annual mean transport and seasonal variability fit in the range of previous estimates (DiMarco et al. 2001 for a review). 
Fig. 3 shows the annual mean meridional overturning (zonally integrated circulation) based on an average of the monthly fields. Like in previous modelling studies, the meridional overturning circulation is mainly intensified in the first $500 \mathrm{~m}$, South of the Equator. The shallow cell connects the Tropics to the Equator and transports $13 \times 10^{6} \mathrm{~m}^{3} \mathrm{~s}^{-1}$. Below $3000 \mathrm{~m}, 6 \times 10^{6} \mathrm{~m}^{3} \mathrm{~s}^{-1}$ moves northward up to $12^{\circ} \mathrm{S}$. This deep inflow is compensated by a southward flow around $1000 \mathrm{~m}$. This pattern, though similar to other general circulation models, is not consistent with recent hydrographic inversions. Especially, Ganachaud et al. (2000) still find a northward flow of $10.2 \pm 3 \times 10^{6}$ $\mathrm{m}^{3} \mathrm{~s}^{-1}$ at $8^{\circ} \mathrm{S}$ using a global inversion of the WOCE data, whereas only $4 \times 10^{6} \mathrm{~m}^{3} \mathrm{~s}^{-1}$ remains at this latitude in our reference circulation. Moreover, as referenced in the introduction, most of the recent hydrographic inversions show that between 11 to $23 \times 10^{6} \mathrm{~m}^{3} \mathrm{~s}^{-1}$ of deep and bottom waters should propagate northward at $32^{\circ} \mathrm{S}$. Our estimate is significantly lower.

In the reference circulation, the southward energy flux across $32^{\circ} \mathrm{S}$ is $1.1 \mathrm{PW}\left(1 \mathrm{PW}=10^{15} \mathrm{~W}\right)$. This flux is the sum, scaled to $\mathrm{PW}$, of the product of the temperature referenced to $0^{\circ} \mathrm{C}$ by the velocity across the section. At this section, Sloyan and Rintoul (2001) estimate a southward flux of

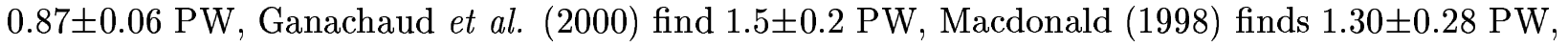
Toole and Warren (1993) find 1.67 PW. The reference circulation fits in the broad range of possible values. Our maximal southward energy flux is $1.3 \mathrm{PW}$ at $14^{\circ} \mathrm{S}$ and is due to both the presence of the Indonesian throughflow and the heat gained in the northern Indian Ocean. In this simulation, the restoring to Levitus climatology also provides other sources and sinks of heat.

For the throughflow, Ganachaud et al. (2000) reported an westward energy flux of $1.36 \pm 0.15$ PW across the Java Australia Dynamic Experiment section (Fieux et al. 1994). In our reference circulation and for this section located around $115^{\circ} \mathrm{E}$, the Indonesian throughflow carries two-fold less energy flux. Our energy flux is smaller because our throughflow transport is $33 \%$ smaller than Ganachaud et al. (2000) estimate and also because our transport weighted temperature is weaker. However, from temperature-current meters, Vranes et al. (2001) estimate an westward flux of 0.55 PW within the Makassar Strait from December 1996 to July 1998. Again, the model fits the range 
of published estimates.

\section{Minimization}

\subsection{Step one}

The minimization starts from the first guess which is the ending state of the year-10 of the spin up. The forward model and its adjoint undergo several iterations to minimize the cost function of year-11 (Eq. 1). During this process, no restoring to Levitus fields is activated at any depth since the assimilation of Levitus fields at the sea surface should rectify the drift of the model.

Fig. 4ab detail the contributions of cost function terms. Each term is normalized so that a value of one (level of consistency) means that the term is consistent with its a priori error. Iteration zero corresponds to the forward model run from the first guess before any changes are made in the control variables. The scale of the Y-axis being logarithmic, contributions from the control variables are not plotted at iteration zero.

Initially, the major misfits relate to the CTD temperature and to the Levitus temperature and salinity climatology. The misfit to CTDs is twenty-fold less in the salinity than in the temperature. That is, most of the modifications in the interior stratification will be due to the temperature constraint. Misfits to the sea surface climatology are mainly due to errors in surface forcings and mixed layer physics that generate a drift of the forward model. Misfits to the CTD observations mainly come from errors in the first guess. The assimilation is stopped at iteration twenty to prevent an overfitting of the model to the surface climatology. As Fig. 4a shows, misfits to the CTD observations are still slightly above the consistency level at iteration twenty. Ten more iterations bring misfits to CTD observations at a consistency level but results in a overfitting of the model to the sea surface climatology. Since no significant differences appears between the estimated circulation from iteration twenty and those from iteration thirty, step one is stopped at iteration twenty. 
In order to investigate how the misfit to the CTD temperature is distributed in the vertical, Fig. 5ab shows this misfit scaled by its error along the meridional WOCE section I9 (Fig. 1). For reason of clarity, only the absolute value of the scaled misfit is represented. Before the assimilation (Fig. 5a), the largest misfit (larger than a factor 40) occurs at depth. This vertical structure reflects those of the error in the CTD temperature which is the weakest at depth (Fig. 2a). Hence, because the deep circulation has less spatial and temporal variability (a criteria used for constructing the error on CTDs), CTD data will mostly constrain the deep circulation. After the assimilation (Fig. 5b), most of the misfit has been significantly reduced. Some regions still exhibit important misfits. Continuing the iterations decrease these local residuals but again this does not lead to any detectable changes in the meridional overturning circulation.

Fig. 4ab show that the major changes in the control variables, relative to their error, concern the first guess temperature field and the surface heat flux and also, in a lesser extent, the surface freshwater flux and the first guess salinity field. The wind stress is not directly controlled by the set of observations of temperature and salinity used in the assimilation since it redistributes heat and salt through the Ekman velocities. This is probably why it is not as much changed as the other surface forcing fields. This is not a limitation of the method but a limitation of the assimilated observations. Velocity observations would certainly constrain the wind stress more efficiently. At the open boundaries, the level of consistency of the temperature is the same as those of the salinity. We could have expected a larger consistency for the temperature in the same way as the first guess fields. The may be due to the fact that within a year, information from the open boundary do not have the time to influence the interior circulation for such a large basin.

\subsection{Step two}

As explained in section 2, a new first guess is built from step one. In this first guess, interior velocities are adjusted to the new stratification. These adjusted fields are obtained by running the forward model with the control variables estimated during step one. The open boundary velocities 
are now adjusted by minimizing cost function given in Eq. 2. The constraint on vertical velocities forces the adjoint equations to control velocities at the open boundaries.

At iteration 0 of this second step, the cost concerning the vertical velocities is ten-fold higher than its level of consistency (Fig. 4c). Most of the minimization occurs in the first six iterations. After twenty iterations, this cost is divided by three but remains three-fold too large. This may indicate either that errors in the model prevent it from reaching the consistency level (in the 4Dvariational problem, the model is considered as perfect) or that errors in the vertical velocities are underestimated.

\section{Estimated ocean circulation}

\subsection{Estimated circulation with a $10 \times 10^{6} \mathrm{~m}^{3} \mathrm{~s}^{-1}$ Indonesian Throughflow}

Fig. 6a shows the annual mean meridional overturning obtained after step one of the assimilation. The circulation above $1000 \mathrm{~m}$ has not changed compared to the overturning circulation without assimilation (Fig. 3). In contrast, the overturning below $1000 \mathrm{~m}$ is intensified. This new deep interior circulation is closed at the southern open boundary by strong vertical velocities. That is, the southern open boundary is not consistent with the interior circulation after step one.

After step two, the open boundary velocities are adjusted to the interior circulation (Fig. $6 \mathrm{~b}$ ). The constraint on the vertical velocity provides open boundary velocities in geostrophic balance with the density at the open boundary. This adjustment results in an increase by $2 \times 10^{6} \mathrm{~m}^{3} \mathrm{~s}^{-1}$ of the deep overturning. The adjustment of the open boundary velocities are thus necessary in our assimilation of WOCE hydrography and our final estimation is those obtained after step two.

The assimilation of the hydrography produces an increase by $11 \times 10^{6} \mathrm{~m}^{3} \mathrm{~s}^{-1}$ of the deep overturning (Figs. 6b and 3). $17 \times 10^{6} \mathrm{~m}^{3} \mathrm{~s}^{-1}$ of deep and bottom waters moves northward up to $10^{\circ} \mathrm{S}$ below $3200 \mathrm{~m}$. At the Equator we still find a deep northward flow of $7 \times 10^{6} \mathrm{~m}^{3} \mathrm{~s}^{-1}$, value that gradually decreases to $1 \times 10^{6} \mathrm{~m}^{3} \mathrm{~s}^{-1}$ at $10^{\circ} \mathrm{N}$. At $32^{\circ} \mathrm{S}$, our estimate is larger than both Ganachaud 
et al. 's (2000) estimate of $11 \pm 4 \times 10^{6} \mathrm{~m}^{3} \mathrm{~s}^{-1}$. These two estimates that uses WOCE hydrography are consistent at $8^{\circ} \mathrm{S}$. Our deep overturning is deeper by $700 \mathrm{~m}$ although this should be taken with caution since Ganachaud et al. (2000) calculate their solution using neutral surfaces. The assimilation does not change significantly the circulation above $1000 \mathrm{~m}$. This was expected since the major constraint brought by CTD data concerns the deep ocean as demonstrated by Fig. 5 . The assimilation of the surface climatology has not changed the upper meridional overturning circulation since this climatology was also imbedded in the circulation without assimilation through the restoring terms.

A zonal section at $30^{\circ} \mathrm{S}$ of differences in the meridional velocities between the estimated circulation and the reference circulation is shown in Fig. 7. The assimilation of the WOCE hydrography intensifies deep northward boundary currents along Madagascar Plateau $\left(40^{\circ} \mathrm{E}, 4 \times 10^{6} \mathrm{~m}^{3}\right.$ $\mathrm{s}^{-1}$ below $\left.3200 \mathrm{~m}\right)$, Ninety East Ridge $\left(90^{\circ} \mathrm{E}, 4 \times 10^{6} \mathrm{~m}^{3} \mathrm{~s}^{-1}\right)$ and east of Broken Plateau in Perth $\operatorname{Basin}\left(105^{\circ} \mathrm{E}, 15 \times 10^{6} \mathrm{~m}^{3} \mathrm{~s}^{-1}\right)$. Between 1000 and $3200 \mathrm{~m}$, southward currents are intensified along the Australian continental slope, west of Ninety East Ridge, above the Indo-Pacific Ridge, and in the Agulhas current.

Fig. 7 also shows that southward velocities in the core of the Agulhas current decrease. The Agulhas current transports $5 \times 10^{6} \mathrm{~m}^{3} \mathrm{~s}^{-1}$ less in the estimated circulation than in the reference one. Its seasonal variation has the same amplitude in both circulations. The Mozambique Channel mean transport is increased by $4 \times 10^{6} \mathrm{~m}^{3} \mathrm{~s}^{-1}$, with a minimum decreased by $3 \times 10^{6} \mathrm{~m}^{3} \mathrm{~s}^{-1}$ in February and a maximum unchanged.

The southward energy flux at $32^{\circ} \mathrm{S}$ is slightly increased by $0.1 \mathrm{PW}$ in the estimated circulation compared to the reference circulation (Fig. 8). At $3^{\circ} \mathrm{N}$, the estimated circulation transports 0.2 PW less energy southward than in the reference circulation. This is a consequence of the decrease of the surface heat gain by the ocean. Removing the restoring to the sea surface climatology in the reference circulation would lead to a significant increase in sea surface temperatures. Hence, the assimilation decreases the surface heat flux so that the increase in surface temperatures is 
removed when no restoring is applied. However, the assimilation produces too large a decrease in the surface heat flux since a forward run from the estimated circulation shows that the heat content decreases within the upper $500 \mathrm{~m}$. According to the errors bars set on surface observations (CTD and Levitus) and the constraints applied during the assimilation, it is not possible to get accurate estimates of the upper circulation and heat budget.

In the reference circulation, the deep circulation below $1000 \mathrm{~m}$ does not contribute to the southward energy flux. In the estimated circulation and south of $3^{\circ} \mathrm{S}$, the deep circulation below $1000 \mathrm{~m}$ transports between 0.06 and $0.12 \mathrm{PW}$ and contributes by 5 to $10 \%$ to the total southward flux. Its contribution increases to $30 \%$ around $10^{\circ} \mathrm{N}$ because the southward energy flux of the upper circulation becomes marginal.

\subsection{Sensitivity to the ITF transport}

Two experiments were made to vary the annual mean Indonesian Throughflow while keeping the same seasonal variation as the previous experiment with a $10 \times 10^{6} \mathrm{~m}^{3} \mathrm{~s}^{-1}$ throughflow. One experiment has no annual mean throughflow and the other a $30 \times 10^{6} \mathrm{~m}^{3} \mathrm{~s}^{-1}$ throughflow. For both experiments, reference and estimated overturning circulations are shown in Fig. 9. The estimated circulation is produced in the same way as the experiment with a $10 \times 10^{6} \mathrm{~m}^{3} \mathrm{~s}^{-1}$ throughflow. Whatever the Indonesian Throughflow is, the estimated circulation always shows that between 15 to $19 \times 10^{6} \mathrm{~m}^{3} \mathrm{~s}^{-1}$ move northward below $3200 \mathrm{~m}$ at $32^{\circ} \mathrm{S}$, of which $7 \times 10^{6} \mathrm{~m}^{3} \mathrm{~s}^{-1}$ reach the Equator. North of the throughflow and above $1000 \mathrm{~m}$, the overturning circulation does not change with the throughflow transport. The only change that occurs above $1000 \mathrm{~m}$ is the southward returning currents south of the Indonesian passages as a response of the throughflow change.

Fig. 8 shows the influence of the throughflow magnitude on the meridional energy flux. The higher the westward transport through the Indonesian passage, the larger the southward energy flux. $60 \%$ of the increase in the westward energy flux at the throughflow open boundary is transported to the South Africa-Australia open boundary without changing the heat flux at the surface. The remaining part goes in heat storage change. This heat storage change, which mostly occurs in the 
first $500 \mathrm{~m}$, is not large enough to be controlled by the constraints of the assimilation. In contrast, the estimated northward energy flux that originates from the South Africa-Australia open boundary below $3200 \mathrm{~m}$ is robust $\left(0.07 \mathrm{PW}\right.$ at $\left.32^{\circ} \mathrm{S}\right)$ to our changes in the throughflow transport.

\section{Discussion}

The main goal of this study was to investigate the presence of a deep meridional overturning in the Indian Ocean from a 4D-variational assimilation of WOCE hydrography and surface climatology within a primitive equation model. The observations were used to constrain the initial state in temperature and salinity, surface forcings and open boundaries. Because of the lack of sensitivity of the cost function to the velocities at the open boundary, these velocities were constrained in a second step of the assimilation where large vertical velocities are penalized along the open boundaries.

Our study brings an answer about the existence of a deep overturning in the Indian ocean. For three values of the Indonesian Throughflow, an estimated circulation dynamically consistent with the observations was found. With a $10 \times 10^{6} \mathrm{~m}^{3} \mathrm{~s}^{-1}$ Indonesian Throughflow, the estimated circulation produces a deep overturning below $1000 \mathrm{~m}$. This overturning was weak in the first guess. The northward flow of bottom waters transports $17 \times 10^{6} \mathrm{~m}^{3} \mathrm{~s}^{-1}$ at $32^{\circ} \mathrm{S}$ below $3200 \mathrm{~m}, 7 \times 10^{6} \mathrm{~m}^{3}$ $\mathrm{s}^{-1}$ at the Equator, and reaches the latitude of $10^{\circ} \mathrm{N}$. Most of this northward flow of bottom waters is balanced by a southward flow of deep waters between 1000 and $3200 \mathrm{~m}$. Consequently, the energy flux carried by this deep overturning cell is restricted to $0.1 \mathrm{PW}$ at $32^{\circ} \mathrm{S}$, that is only $10 \%$ of the southward energy flux at this latitude. This deep overturning is also present with almost the same transport $\left( \pm 2 \times 10^{6} \mathrm{~m}^{3} \mathrm{~s}^{-1}\right)$ in estimated circulations that have no annual mean Indonesian Throughflow and a $30 \times 10^{6} \mathrm{~m}^{3} \mathrm{~s}^{-1}$ annual mean throughflow. Waters that originate from the throughflow are warm and concern the upper circulation which may explain why the estimated deep overturning circulation is not sensitive to the throughflow transport. It has also been verified that starting from a different first guess (further apart from the hydrography) leads to the same intensification of the deep overturning in the estimated circulation. 
Our estimated deep overturning in the Indian Ocean contrast with the usual weak deep circulation found in primitive equation models (Wacongne and Pacanowski 1996; Garternicht and Schott 1997; Lee and Marotzke 1997, 1998; Zhang and Marotzke 1999). The assimilation generates a deep overturning that fits to the range $\left(11-23 \times 10^{6} \mathrm{~m}^{3} \mathrm{~s}^{-1}\right.$ at $\left.32^{\circ} \mathrm{S}\right)$ of recent estimates from hydrographic studies (Robbins and Toole 1997; Macdonald 1998; Ganachaud et al. 2000; Sloyan and Rintoul 2001). Observing the meridional velocities shows that the assimilation of WOCE hydrography is responsible for boundary current reconstructions. Bryden and Beal (2001), Ganachaud et al. (2000), Sloyan and Rintoul (2001) and Macdonald (1998) also found that the deep northward flow is mainly balanced by a southward flow between $1000 \mathrm{~m}$ and $3000 \mathrm{~m}$. The depth of this southward flow is alsoThis assimilation is thus able to extract the small scale structures of the hydrography (same scales as those seen by hydrographic studies) to improve the initial state of the primitive equation model.

Running the forward model from its estimated initial state and forcings for 10 years shows a slow but regular decrease of the deep overturning from $17 \times 10^{6} \mathrm{~m}^{3} \mathrm{~s}^{-1}$ to $12 \times 10^{6} \mathrm{~m}^{3} \mathrm{~s}^{-1}$. The misfit to the CTDs increases with the year which shows that the model cannot stay consistent with errors on CTD observations at depth. We think that errors in the model physics are the source of the slow drift from its dynamically consistent estimated circulation. For instance, the misrepresentation of some key passages in the bathymetry, the homogenous spatial distribution of the vertical mixing, the lack of horizontal resolution may result in the impossibility of maintaining the deep overturning to its estimated level.

If the estimated deep circulation is robust to change in the Indonesian Throughflow and first guess, the upper circulation and consequently its associated energy flux are less constrained by the set of data we used. This is best illustrated by the rapid decrease in the heat content within the first $500 \mathrm{~m}$ when the estimated initial state is run over several years with the optimal surface forcings. This decrease may occur for two reasons. Firstly, the mixed layer physics is not parameterized adequately with a constant vertical diffusion coefficient and a convective mixing scheme. If the 
surface heat and freshwater flux is not adequately transferred in the vertical, even perfect surface forcings would not prevent a drift of subsurface properties. An assimilation with an appropriate mixed layer physics and its adjoint would answer to this problem. Such a physics was not included in our assimilation because its adjoint was still under development. Secondly, because of the natural high spatial and temporal variability of the upper circulation, errors in the observations (CTDs and climatology) are too large at the surface to produce accurate estimates of the surface heat and freshwater flux. To overcome the effect of large errors in the observations at the surface, a constraint that penalizes the temporal drift could be added to the cost function. The drift should not exceed what we think the interannual variability is. Such a constrain should control the heat flux divergence of the basin.

Acknowledgments: This work has been supported by the US National Science Foundation and by the Centre National de la Recherche Scientifique (CNRS). Numerical experiments used the National Partnership for Advanced Computational Infrastructure (NPACI, USA) and the Institut du Développement et des Resources en Informatique Scientifique (IDRIS, France). 


\section{REFERENCES}

Biastoch, A., and W. Krauß, 1999: The role of mesoscale eddies in the source regions of the Agulhas Current. J. Phys. Ocean., 29, 2303-2317.

DiMarco, S. F., P. Chapman, W. D. Nowlin, P. Hacker, K. Donohue, J. Toole and G. Johnson, 2001: Volume transport and property distributions of the Mozambique Channel. Deep-Sea Res., in press.

ETOPO5, 1988: Data Announcement 88-MGG-02, Digital relief of the Surface of the Earth. NOAA, National Geophysical Data Center, Boulder, Colorado.

Fieux, M., C. Andrié, P. Delecluse, A. G. Ilaude, A. Kartavtseff, F. Mantisi, R. Molcard, and J. C. Swallow, 1994: Measurements within the Pacific-Indian Oceans Throughflow region. Deep-Sea Res., Part I, 41, 1091-1130.

Fu, L.-L., 1986: Mass, heat and freshwater fluxes in the South Indian Ocean. J. Phys. Ocean., $16,1683-1693$.

Ganachaud, A., C. Wunsch, J. Marotzke, and J. Toole, 2000: Meridional overturning and large-scale circulation of the Indian Ocean. J. Geophys. Res., 105, 26117-26134.

Garternicht, U., and F. Schott, 1997: Heat fluxes of the Indian Ocean from a global eddyresolving model. J. Geophys. Res., 102, 21,147-21,159.

Garrett, C. J. R., and W. H. Munk, 1975: Space-time scales of internal waves. A progress report. J. Geophys. Res., 80, 291-297.

Giering, R., and T. Kaminski, 1998: Recipes for adjoint code construction. ACM Trans. Math., 24, 437-474.

Gilbert, J. C., and C. Lemaréchal, 1989: Some numerical experiments with variable-storage quasi-Newton algorithms. Math. Programm., 45, 407-435. 
Gordon, A. L., R. D. Susanto, and A. Ffield, 1999: Throughflow within Makassar Strait. Geophys. Res. Letters, 26, 3325-3328.

Le Dimet, F.-X., and O. Talagrand, 1986: Variational Algorithms for Analysis and Assimilation of Meteorological Observations. Theoretical Aspect. Tellus 38A, p. 97-110.

Lee, T., and J. Marotzke, 1997: Inferring meridional mass and heat transports in the Indian Ocean by combining a general circulation model with climatological data. J. Geophys. Res., $102,10,585-10,602$.

Lee, T., and J. Marotzke, 1998: Seasonal cycles of meridional overturning and heat transport of the Indian Ocean. J. Phys. Ocean., 28, 923-943.

Levitus, S., R. Burgett, and T. Boyer, 1994: World Ocean Atlas 1994, vol.3, Salinity, and vol. 4, Temperature. NOAA Atlas NESDIS 3 \& 4, U.S. Dep. of Comm., Washington, D. C. Macdonald, A., 1998: The global ocean circulation: a hydrographic estimate and regional analysis. Prog. in Ocean., 41, 281-382.

Marotzke, J., R. Giering, K. Q. Zhang, D. Stammer, C. Hill, and T. Lee, 1999: Construction of the adjoint MIT ocean general circulation model and application to Atlantic heat transport sensitivity. J. of Geophys. Res., 104, 29529-29547.

Marshall, J., C. Hill, L. Perelman, and A. Adcroft, 1997a: Hydrostatic, quasi-hydrostatic, and non-hydrostatic ocean modeling. J. Geophys. Res., 102, 5733-5752.

Marshall, J., A. Adcroft, C. Hill, L. Perelman, and C. Heisey, 1997b: A finite-volume, incompressible Navier-Stokes model for studies of the ocean on parallel computers. J. Geophys. Res., 102, 5753-5766.

Robbins, P. E., and J. M. Toole, 1997: The dissolved silica budget as a constraint on the meridional overturning circulation of the Indian ocean. Deep-Sea Res., 44, 879-906. 
Sloyan, B. M., and S. R. Rintoul, 2001: The southern limb of the global deep overturning circulation. J. Phys. Ocean., 31, 143-173.

Stammer, D., C. Wunsch, R. Giering, Q. Zhang, J. Marotzke, J. Marshall, and C. Hill, 1997: The global ocean circulation estimated from TOPEX/POSEIDON Altimetry and a general circulation model. Center for Global Change Science Report, bf 49, MIT, 40pp.

Thacker, W. C., and R. B. Long, 1988: Fitting dynamics to data. J. Geophys. Res., 93, $1227-1240$.

Toole, J. M., and B. A. Warren, 1993: A hydrographic section across the subtropical South Indian Ocean. Deep-Sea Res., 40, 1973-2019.

Vranes, K., A. L. Gordon, and A. Ffield, 2001: The Heat Transport of the Indonesian Throughflow and Implications for the Indian Ocean Heat Budget. Deep-Sea Res., in press.

Wacongne, S., and R. Pacanowski, 1996: Seasonal heat transport in a primitive equations model of the tropical Indian Ocean. J. Phys. Ocean., 26, 2666-2699.

Zhang, Q., and J. Marotzke, 1999: The importance of open-boundary estimation for an indian ocean gcm-data synthesis. J. Mar. Res., 57, 305-334. 


\section{FIGURE CAPTIONS}

1. Bathymetry of our $1^{\circ}$ resolution model and WOCE CTD lines. The I9 WOCE section is indicated.

2. Vertical profiles of the error in a) CTD temperature, b) CTD salinity, c) first guess temperature, d) first guess salinity, and e) open boundary (OB) velocity.

3. Meridional transport as a function of latitude (upper panel) and annual mean meridional overturning (lower panel) of the model without assimilation (units $\times 10^{6} \mathrm{~m}^{3} \mathrm{~s}^{-1}$ ). Note that in the region of the Indonesian Throughflow (area bounded by the dashed line), the flow is divergent and isolines depict constant transport integrated from the bottom.

4. a) Total cost for step one as a function of iteration number and contributions from misfits to CTD observations and climatology and from first guess control variables. b) Contributions from the other control variables. Each Cost is normalized by its number of elements. c) Same as a) but for step two of the assimilation.

5. Absolute value of the model-CTD temperature misfit scaled by the error in the temperature of the CTDs along the I9 WOCE section. Upper panel: state before step one. Lower panel: state after step one.

6. a) Estimated meridional transport as a function of latitude (upper panel) and estimated annual mean meridional overturning (lower panel) after step one of the assimilation. b) Same as a) but after step two of the assimilation. Units $\times 10^{6} \mathrm{~m}^{3} \mathrm{~s}^{-1}$.

7. Difference of meridional velocities $(\mathrm{m} / \mathrm{s})$ at $30^{\circ} \mathrm{S}$ between the estimated circulation and the reference one.

8. Energy flux of the circulation as a function of latitude for the reference circulation and the estimated circulation with a $10 \times 10^{6} \mathrm{~m}^{3} \mathrm{~s}^{-1}$ Indonesian throughflow (ITF). Also shown are the estimated fluxes of the estimated circulations with an annual mean ITF of $0 \times 10^{6} \mathrm{~m}^{3}$ $\mathrm{s}^{-1}$ and $30 \times 10^{6} \mathrm{~m}^{3} \mathrm{~s}^{-1}$. 
9. Upper panels show the reference (left) and estimated (right) meridional overturnings (units $\times 10^{6} \mathrm{~m}^{3} \mathrm{~s}^{-1}$ ) with no annual mean Indonesian Throughflow. Lower panel same as upper with a throughflow of $30 \times 10^{6} \mathrm{~m}^{3} \mathrm{~s}^{-1}$. 

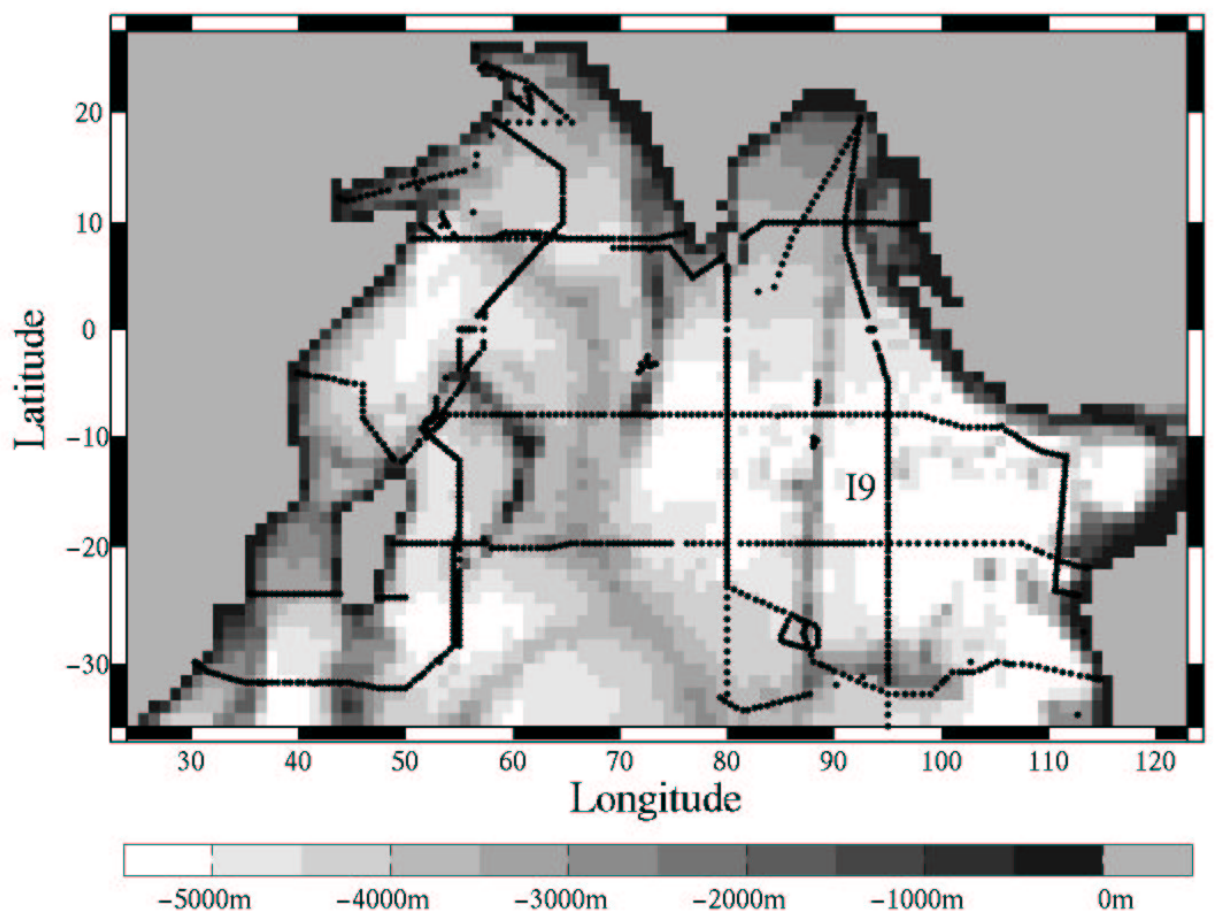

Figure 1: 

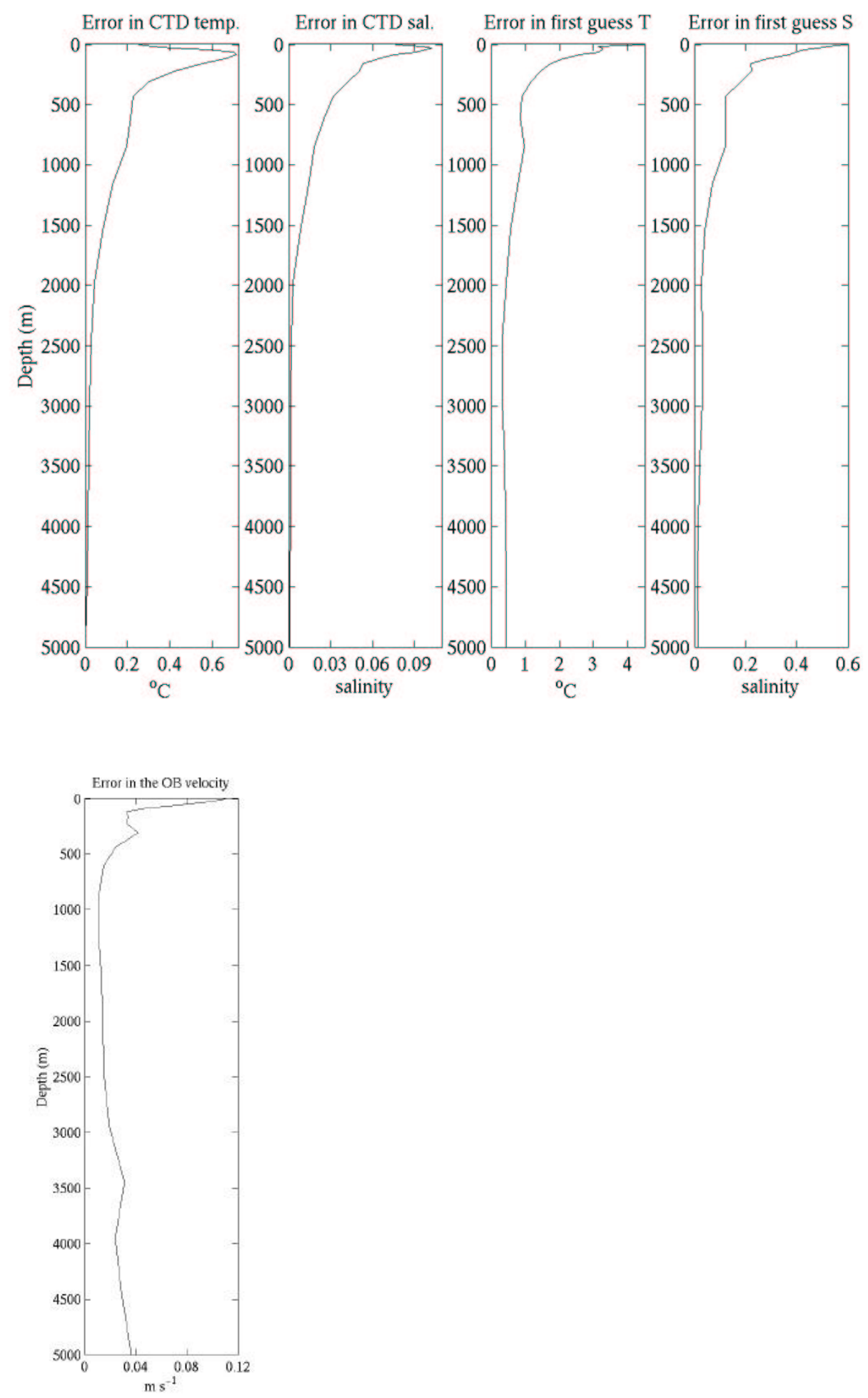

Figure 2: 

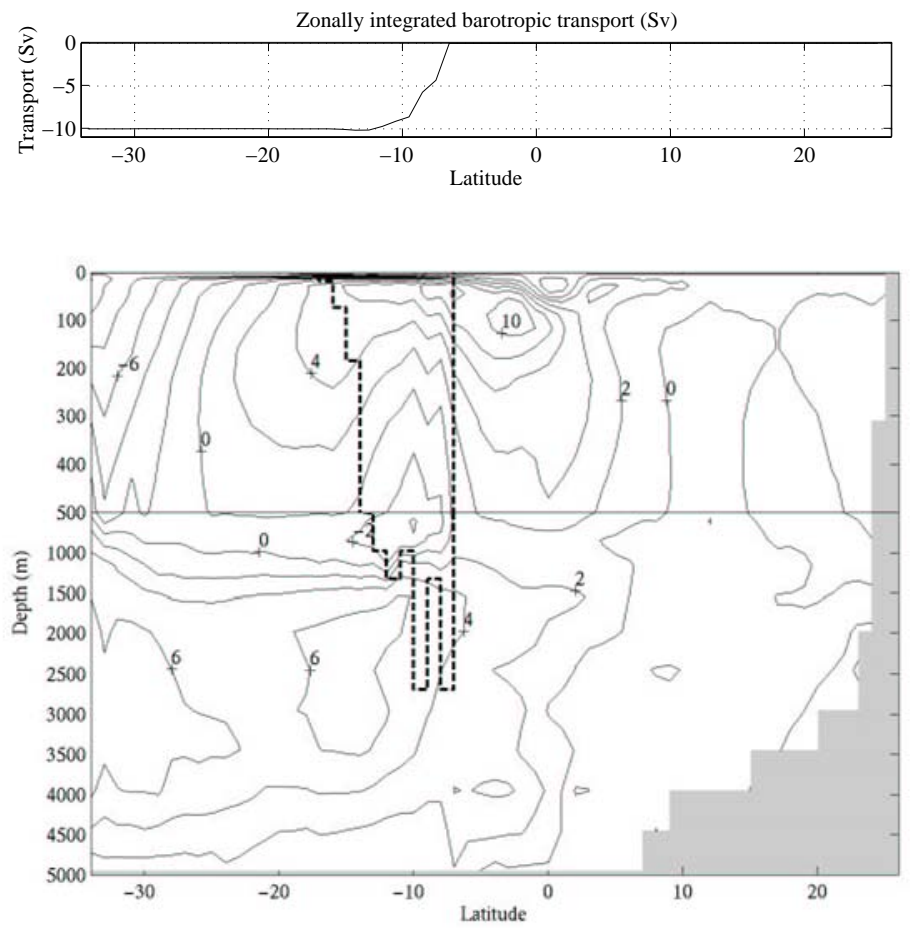

Figure 3: 

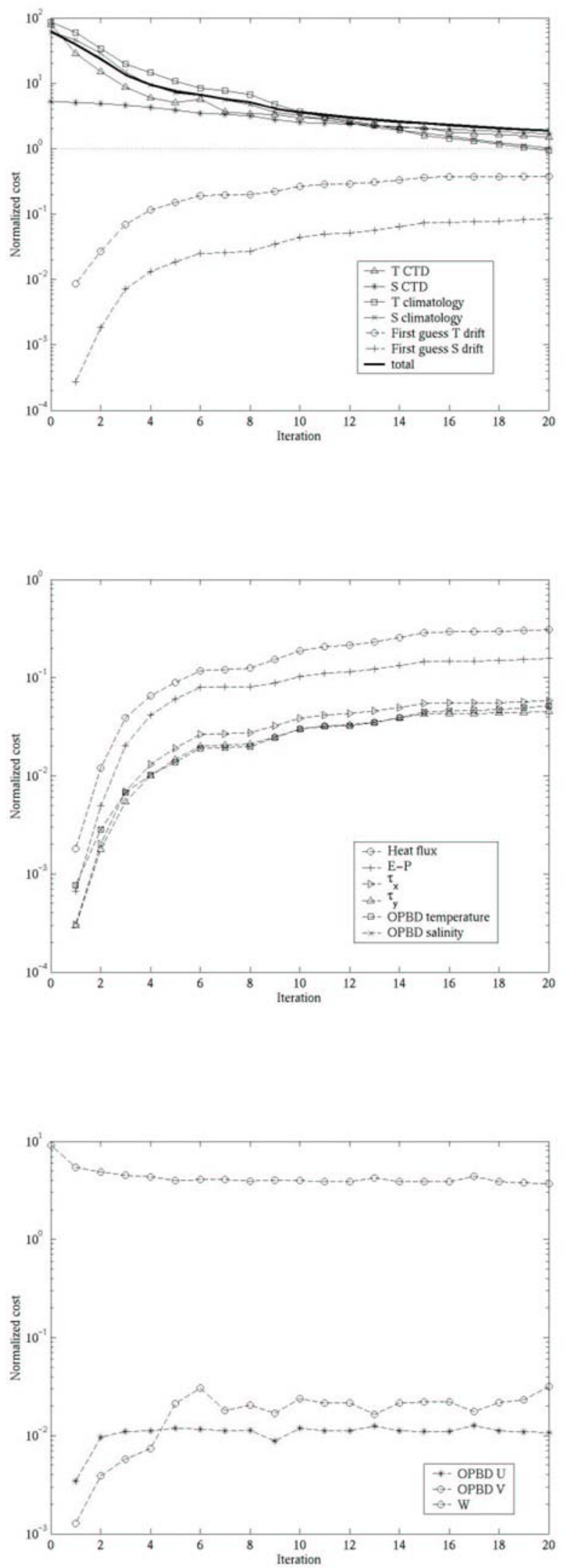

Figure 4: 


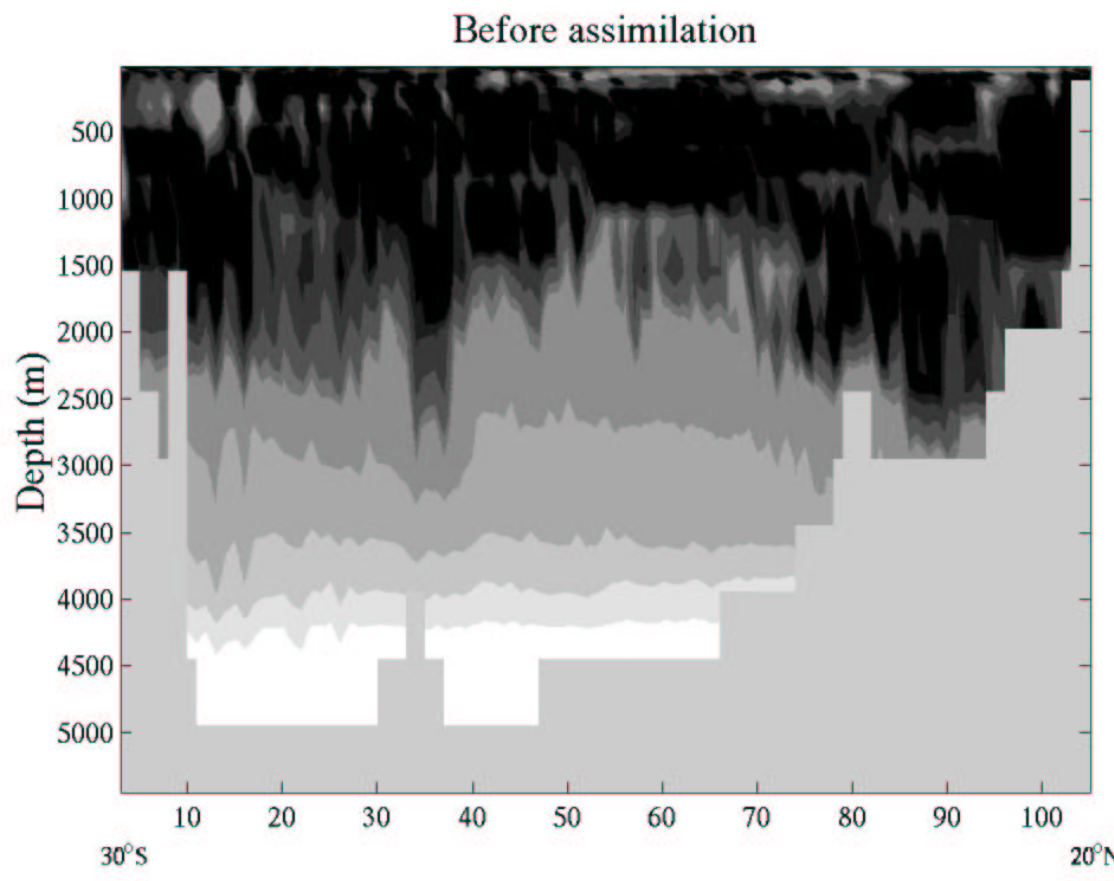

After assimilation

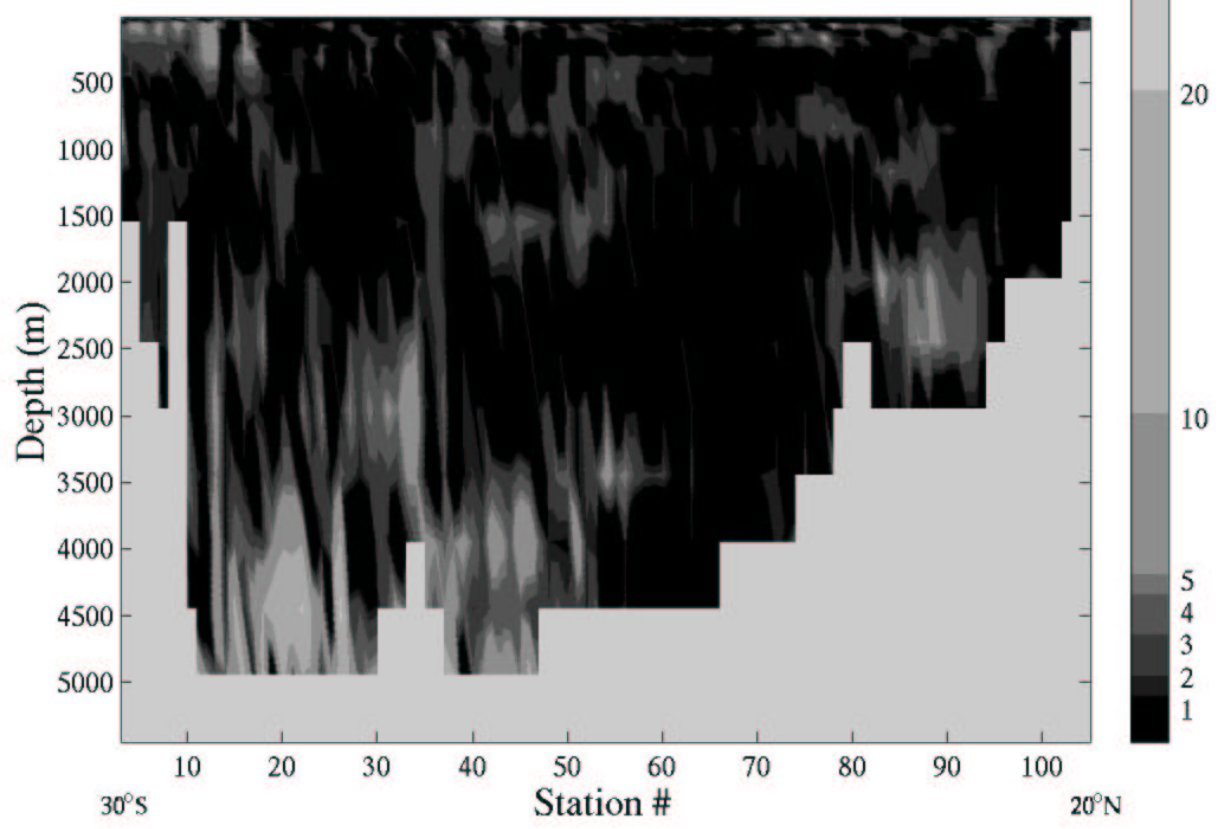

Figure 5: 

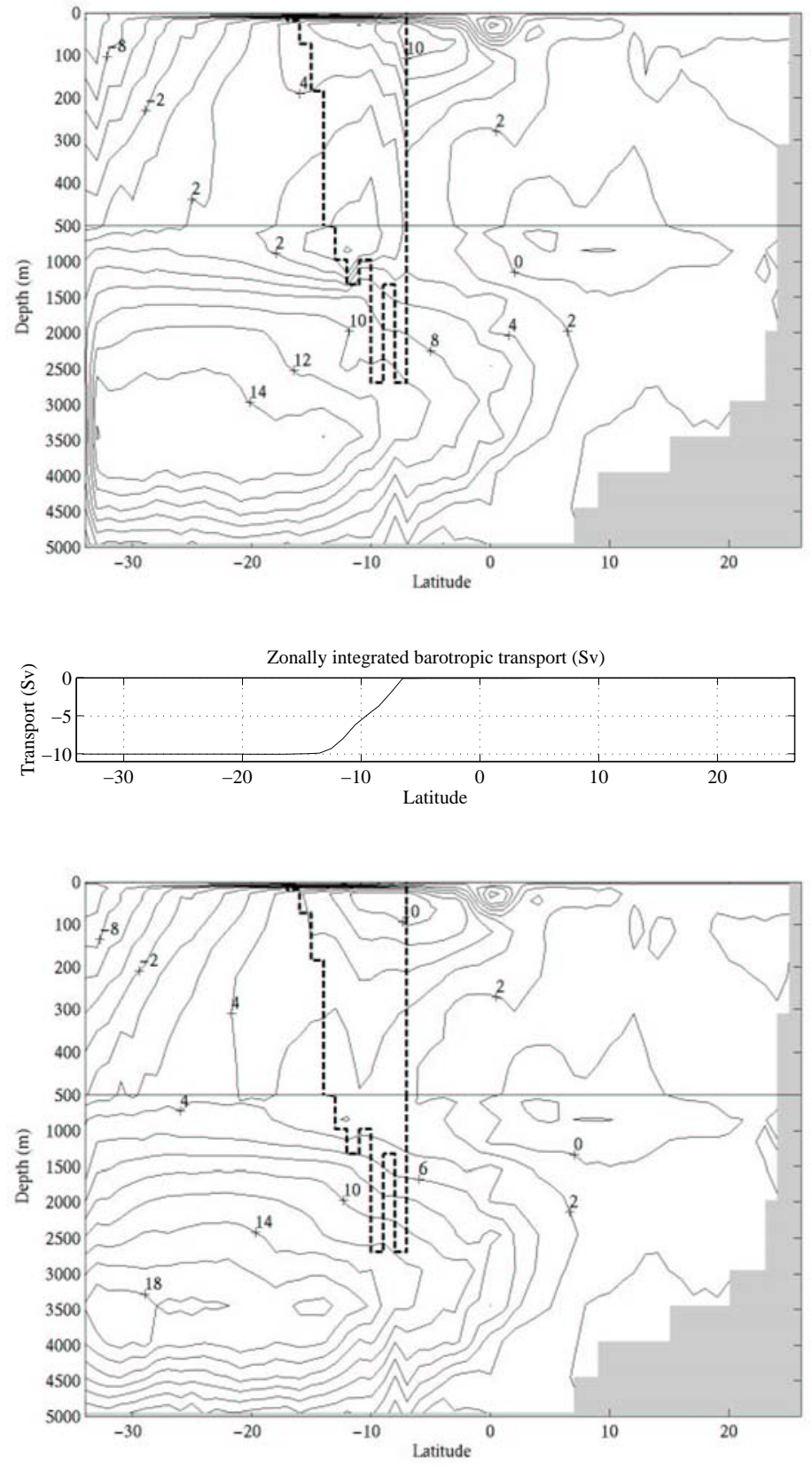

Figure 6: 


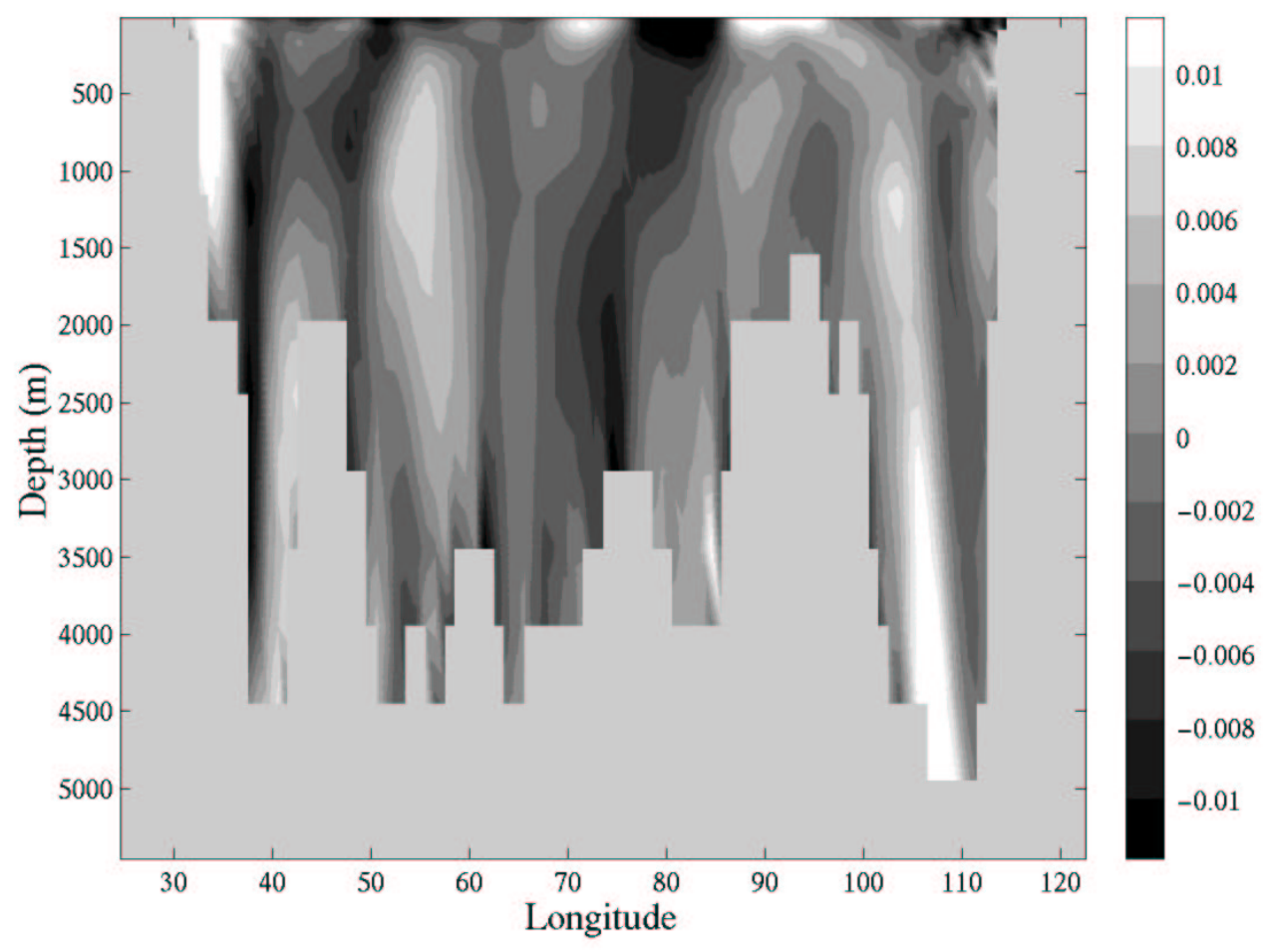

Figure 7: 


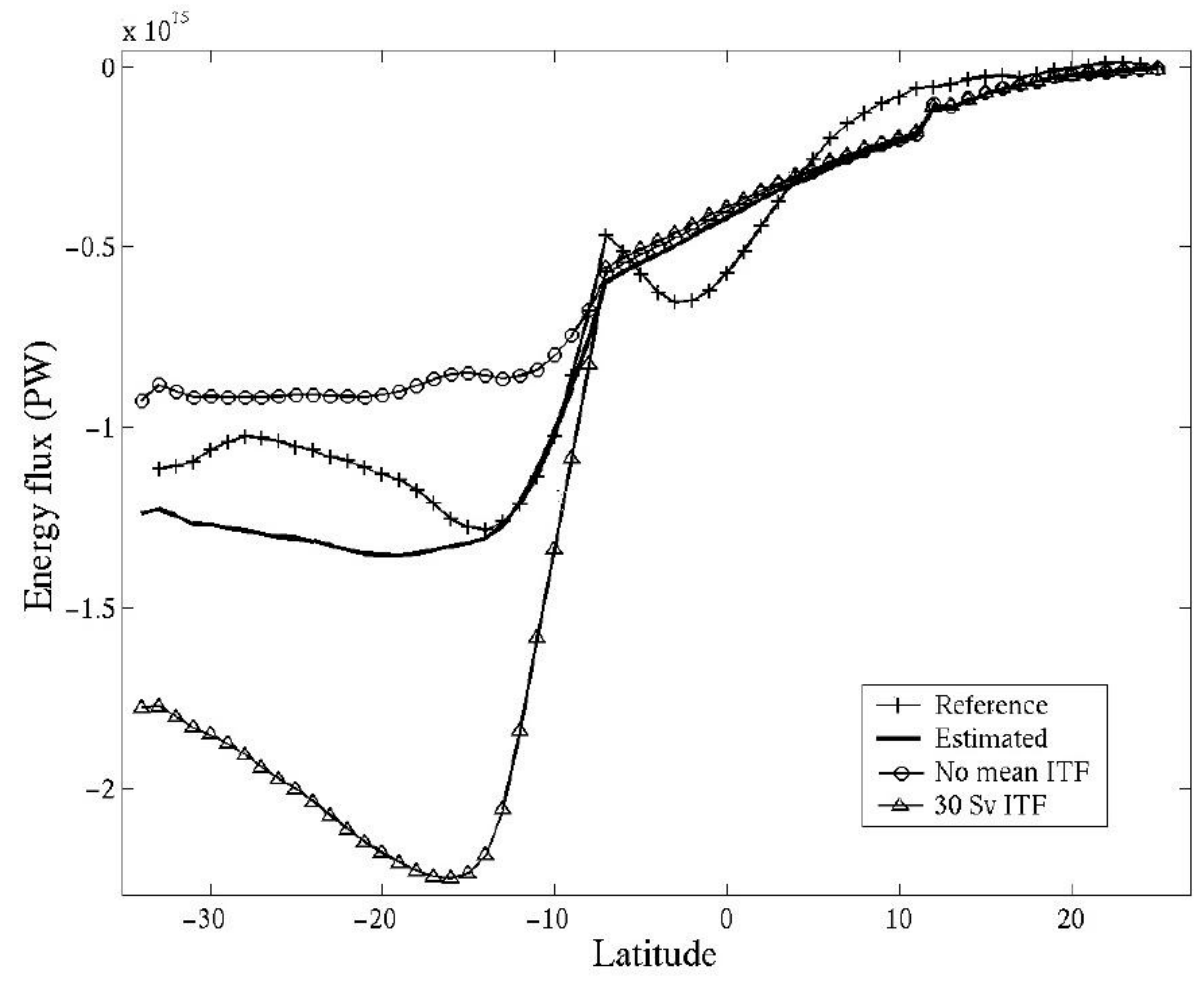

Figure 8: 

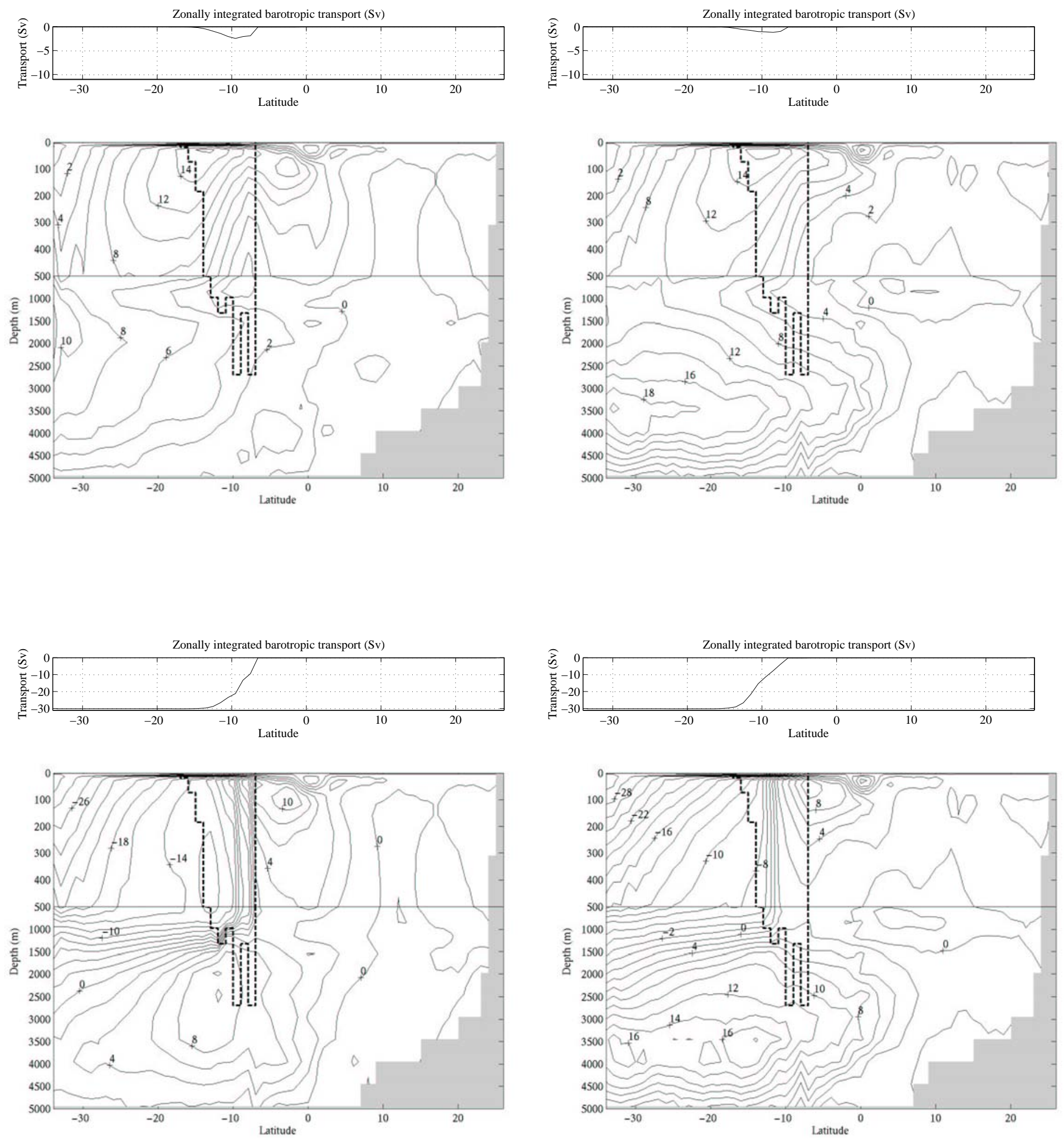

Figure 9: 